\title{
Minimum Left Atrial Volume
}

\section{Evaluated by 3D Echocardiography \\ Predicts Atrial Fibrillation}

\section{Recurrences After a First}

Radiofrequency Catheter Ablation for Paroxysmal Episodes

Lavinia-Lucia MATEI a, b, Liviu-Nicolae GHILENCEA ${ }^{a}$, b, Gabriel-Cristian BEJANa, Sebastian STOICAc, Ruxandra DRAGOI-GALRINHO'c, Calin SILISTEa, c,

Dragos VINEREANU ${ }^{\mathrm{a}, \mathrm{b}}$

a"Carol Davila" University of Medicine and Pharmacy, Bucharest, Romania

bDepartment of Cardiology, Elias Emergency University Hospital, Bucharest, Romania

'Department of Cardiology and Cardiovascular Surgery, Emergency University Hospital, Bucharest, Romania

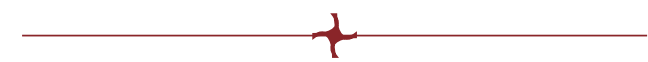

\begin{abstract}
Background: Atrial fibrillation (AF) is facilitated by an enlarged left atrium (LA) and increased LA mass. Left atrium volume (LAV) has a powerful prognostic value for sinus rhythm (SR) maintenance. Persistent SR may lead to atrial reverse-remodeling; therefore, preprocedural LAV may predict the outcome after $A F$ radiofrequency catheter ablation (RFCA).

Study aim: To evaluate the relationship between $L A$ dimensions and AF recurrences (AFR) using echocardiography.

Methods: We enrolled 40 patients (56 \pm 10 years; $73 \%$ males) who underwent a first RFCA for paroxysmal AF. Bi- (2DE) and three-dimensional (3DE) echocardiography was performed prior to RFCA and at 12-months follow-up. Rhythm control was monitored for up to two years after the intervention by periodic ECG Holter monitoring.

Results: Atrial fibrillation recurrences were recorded in 21 patients (52\%) in the first year after RCFA. The only predictor of outcome from pre-ablation LA parameters was 3DE minimum LAVi $(p=0.042)$, that explained $21.4 \%$ of AF recurrences in the first year, with a cut-off value of $21.29 \mathrm{~mL} / \mathrm{m}^{2}$. The mean $3 D E$ min LAVi was $24.29 \pm 8.01 \mathrm{~mL} / \mathrm{m}^{2}$ and patients without AFR in the first year had a lower LAVi than those with AFR (20.92 $\pm 6.19 \mathrm{~mL} / \mathrm{m}^{2}$ vs. $\left.27.25 \pm 8.43 \mathrm{~mL} / \mathrm{m}^{2}, p=0.028\right)$. One year after RFCA, a decrease in
\end{abstract}

Address for correspondence:

Prof. Dr. Dragoș Vinereanu

Mailing address: Splaiul Independenței 169, Emergency University Hospital, 050098 Bucharest, Romania

Tel.: 004021.316.05.09

Email: vinereanu@gmail.com

Article received on the $9^{\text {th }}$ of August 2021 and accepted for publication the $13^{\text {th }}$ of September 2021 
medio-lateral, superior-inferior diameters and volumes were recorded in AF free patients. Eleven patients (27\%) had AF recurrences after the first year and LAV 12-months after RFCA were found to be predictors of long-term outcome, with minimum LAVi as the strongest predictor of recurrences ( $p=0.014$ ), explaining $36 \%$ of episodes, with a cut-off over $22.49 \mathrm{~mL} / \mathrm{m}^{2}$.

Conclusion: Radiofrequency ablation controls LA remodeling in patients with clinical success in terms of AF freedom. Left atrium 3DE volumetry is accurate in predicting RFCA outcome.

Keywords: : atrial fibrillation, atrial fibrillation recurrences, left atrial dimensions, left atrial volume.

\section{INTRODUCTION}

L eft atrium (LA) size assessed by echocardiography has a powerful prognostic value in multiple cardiovascular diseases, including atrial fibrillation (AF) (1). The size of LA determines the risk of $\mathrm{AF}$ recurrence in patients with intended rhythm control.

Echocardiography is essential in evaluating AF effect on LA size and volume, and helps identify patients at risk of AF recurrence after radiofrequency catheter ablation (RFCA) (2). Structural remodeling of LA is asymmetric and the anteroposterior size, usually evaluated in clinical practice, can underestimate LA dimensions. Left atrium volumes (LAV) are more accurate than linear dimensions (3) and, when assessed by three-dimensional echocardiography, the have the advantage of eliminating geometrical assumptions (4).

Echocardiographic predictors for AF recurrence (AFR) were evaluated in multiple studies; depending on the characteristics of the enrolled population, each parameter seems to have its role. In most studies, anteroposterior diameter and LA index volume as a marker of LA dilation predicts an unfavorable outcome after RFCA (5).

\section{METHODS}

\section{tudy design}

Swe enrolled 40 patients who underwent a first RFCA for symptomatic drug-refractory paroxysmal AF in a low-volume ablation centre. We excluded those with non-paroxysmal AF episodes, repeated ablative procedures, ischemic or structural cardiomyopathies, significant valvular diseases, uncontrolled risk factors for AFR (thyroid disease, sleep apnoea, and chronic alcohol abuse). All patients signed an informed consent and the study protocol was approved by the Local Hospital Ethics Committee.

The ablation protocol was the same in all patients. Briefly, LA is accessed through two transseptal punctures (performed only with contrast and pressure control), where two catheters are placed: a circular duodecapolar catheter (Lasso 2151 Biosense Webster, Inc, Diamond Bar, Calif) and an ablation unidirectional catheter (Thermocool Smartouch Biosense Webster, Diamond Bar, Calif). 3D electroanatomic mapping is performed with CARTO (Biosense Webster, Inc) system, and electrograms are filtered and displayed on a commercially available electrophysiological recording system (Cardiolab, GE, Houston, Tex). The ablation lines are placed at the proximal pulmonary vein antrum. Successful isolation is defined by entrance and exit block.

Transthoracic echocardiography was performed prior the procedure and repeated at 12-months follow-up. We used a GE Vivid 9 system (GE Vingmed, Ultrasound, AS, Horten, Norway). All patients were in sinus rhythm (SR) at the time of acquisitions and an average of three cardiac cycles were recorded. Left atrium volumetric assessment was done in a 4- and 2-chamber dedicated optimized view, using area-length method; all volumes were indexed to body surface area. 3DE acquisition of LAV was done in the 4-chamber view at end-expiratory apnoea. Maximum (max) LAV was determined at end-systole, just before mitral valve opening. The LA minimum ( $\mathrm{min}$ ) volume was determined at end-diastole, after mitral valve closure. Image analysis was performed offline using GE Echo PAC software version BT13. All images and measurements were performed by a single operator using a standard protocol, according to guidelines of the European Association of Cardiovascular Imaging guidelines and recommendations of the American Society of Echocardiography. Three-dimensional volumetric evaluation was 
performed using the GE Echo PAC 4D LVQ software, that is designed for the left ventricle but can also be used for LA volumetry (6).

We considered AF recurrence any episode of documented atrial tachyarrhythmia that lasted more than 30 seconds. Periodic assessments were done using 48-hour ECG monitoring and outcome was recorded up to 24 months.

The study aim was to evaluate atrial remodeling using bi- (2DE) and three-dimensional (3DE) echocardiography, and to assess LA volumes as independent predictors for AF recurrence (AFR).

\section{Statistical analysis}

Continuous variables are presented as mean \pm SD (standard deviation) for uniform distribution and comparisons of the central tendency of baseline characteristics and endpoints used Student $t$-test, while abnormally distributed continuous variables are presented as mean (IQR) and non-parametric tests (Mann-Whitney $U$ rank-sum test) were used for comparison. All p-values were two-sided and a p-value $<0.05$ was considered statistically significant. Variables with statistically significant influence over the outcome were processed with univariate linear regression. We used the following criteria to identify predictors for AFR: area under the ROC curve (AUROC) >0.650, Hosmer-Lemeshow goodness-of-fit test $p>0.05$ and $p<0.1$. The odds ratio (OR) was generated for each independent predictor. Previously identified predictors have been computed with multivariate logistic regression. The best model predicting recurrences was selected based on calibration Akaike's Information Criterion (AIC) and Bayesian Information Criterion (BIC) as tests for Goodness-of-Fit with lowest values and Nagelkerke $\mathrm{R}^{2}$ test. A threshold for AFR risk was identified in the training cohort and the sensitivity and specificity identified were reported. Validation of results was done with Hanley \& McNeill test with a p-value $>0.05$. We analyzed the data using SPSS (Statistical Package for the Social Sciences) version 26 software (IBM SPSS Statistics, Armonk, NY, USA; IBM Corp.).

\section{RESULTS}

/ e enrolled 40 patients $(56 \pm 10$ years; $73 \%$ males) who underwent a first RFCA for paroxysmal AF. The mean duration of study monitoring was $2.1 \pm 0.67$ years. Baseline characteristics of the study population are summarized in Table 1.

Mean LVEF was $55.26 \pm 6.40 \%$, and diastolic dysfunction (7) was diagnosed in 25\% (10/40) of patients. In our study group, mean LA anteroposterior (AP) diameter was $39.83 \pm 4.45 \mathrm{~mm}$, and $47.5 \%(19 / 40)$ of patients had a diameter $>40 \mathrm{~mm}$. The mean maximum left atrium volume indexed (LAVi) at baseline was $38.15 \pm 8.78 \mathrm{ml} / \mathrm{m}^{2}$, with $72.5 \%$ (29/40) of patients having a dilated LAVi $\left(>34 \mathrm{~mL} / \mathrm{m}^{2}\right)$.

A total of $52 \%$ (21/40) patients had AFR in the first 12 months, while $27 \%(11 / 40)$ of subjects had AF recurrences after the first year. Prior to the RFCA procedure, no significant differences were observed regarding LA linear dimensions between patients who would develop AFR in the first years and those who would maintain SR, except for 3DE min LAVi that was significantly lower in AF-free pts $(p=0.028)$. Twelve months after the intervention, patients who remained $\mathrm{AF}$ free had lower LA diameters and volumes, assessed by both 2DE and 3DE procedures, while those with $\mathrm{AF}$ recurrences did not show reverse remodeling of LA dimensions (Table 2).

\section{Left atrial dimensions as predictors of outcome}

We evaluated 3D min LAVi's prognostic role regarding ablation outcome, as its baseline value was the only echocardiographic parameter significantly different between the two groups divided by $A F$ recurrences in the first year after RFCA. We determined that $3 \mathrm{DE}$ min $\mathrm{LAVi}$ was a predictor of AF recurrences $(p=0.042)$, explaining $21.4 \%$ of episodes that appeared in the following 12 months after a first RFCA for paroxysmal AF. The calculated cut-off value was $21.29 \mathrm{~mL} / \mathrm{m}^{2}$, with a sensibility of $68.8 \%$ and specificity of $64.4 \%$ (AUROC $=0.701, \quad 95 \% \quad \mathrm{Cl}=0.513-0.889$; $\mathrm{p}=0.061$ ). Patients with a min LAVi over the threshold had a $12 \%$ higher risk of AF recurrence in the first year after RFCA than those with a lower $\min \mathrm{LAVi}(\mathrm{OR}=1.128,95 \% \mathrm{Cl}=1.004-1.268$, $p=0.042$ ).

The equation of prediction was computed as follows: $\operatorname{Ln}(\mathrm{OR}$ for AFR) $=-2.741+0.121 \mathrm{x}$ [baseline 3DE min LAVi]. We validated our result on a 20-patient internal cohort (randomly chosen, respecting the percentages of $52 \%$ : 


\begin{tabular}{|c|c|}
\hline Characteristics & Study population $(\mathrm{n}=40 \mathrm{pts})$ \\
\hline Age at ablation time, years, mean $\pm \mathrm{SD}(95 \% \mathrm{CI})$ & $56 \pm 10(53.33-59.52)$ \\
\hline \multicolumn{2}{|l|}{ Gender, $\mathrm{n}(\%)$} \\
\hline Male & $29(73 \%)$ \\
\hline Female & $11(27 \%)$ \\
\hline Time from AF diagnosis, years, mean $\pm \mathrm{SD}(95 \% \mathrm{CI})$ & $3.45 \pm 2.34(2.7-4.2)$ \\
\hline \multicolumn{2}{|l|}{ Treatment, $\mathrm{n}(\%)$} \\
\hline Propafenone & $16(40 \%)$ \\
\hline Amiodarone & $13(32.5 \%)$ \\
\hline Flecainide & $4(10 \%)$ \\
\hline Betablockers, $\mathrm{n}(\%)$ & $29(72.5 \%)$ \\
\hline Statin, $\mathrm{n}(\%)$ & $16(40 \%)$ \\
\hline ACEI, $\mathrm{n}(\%)$ & $25(62.5 \%)$ \\
\hline \multicolumn{2}{|l|}{ Associated conditions, $\mathrm{n}(\%)$} \\
\hline Arterial hypertension & $27(67.5 \%)$ \\
\hline Dyslipidemia & $19(47.5 \%)$ \\
\hline Type 2 Diabetes Mellitus & $7(17.5 \%)$ \\
\hline $\mathrm{BMI}(\mathrm{Kg} / \mathrm{m} 2)$, mean $\pm \mathrm{SD}(95 \% \mathrm{CI})$ & $29.83 \pm 4.13(28.51-31.15)$ \\
\hline N-terminal fragment of pro BNP, pg/ml, median (IQR) & $141.5(147.5)$ \\
\hline Creatinine clearance, $\mathrm{ml} / \mathrm{min} / 1.73 \mathrm{~m}^{2}$, mean $\pm \mathrm{SD}(95 \% \mathrm{CI})$ & $78.75 \pm 19.78(72.42-85.07)$ \\
\hline \multicolumn{2}{|l|}{ Procedure characteristics } \\
\hline Complete pulmonary vein isolation, $\mathrm{n}(\%)$ & $32(80 \%)$ \\
\hline Atrial substrate ablation, $\mathrm{n}(\%)$ & $5(12.5 \%)$ \\
\hline Cavo-tricuspid ablation, $\mathrm{n}(\%)$ & $3(7.5 \%)$ \\
\hline \multicolumn{2}{|l|}{ Echocardiographic parameters - 2D* } \\
\hline LVEF, \% & $55.26 \pm 6.40(53.21-57.31)$ \\
\hline LV mass, $\mathrm{g} / \mathrm{m} 2$ & $87.20 \pm 13.25(82.96-91.44)$ \\
\hline LA anteroposterior diameter, $\mathrm{mm}$ & $39.83 \pm 4.45(38.40-41.25)$ \\
\hline LA mediolateral diameter, mm & $43.10 \pm 4.27(41.73-44.47)$ \\
\hline LA anterosuperior diameter, $\mathrm{mm}$ & $54.65 \pm 6.21(52.66-56.64)$ \\
\hline LA max volume, $\mathrm{ml} / \mathrm{m} 2$ & $38.15 \pm 8.78(35.32-40.95)$ \\
\hline LA min volume, $\mathrm{ml} / \mathrm{m} 2$ & $20.39 \pm 8.22(17.76-23.02)$ \\
\hline RA diameter, mm & $37.33 \pm 5.19(35.66-38.99)$ \\
\hline $\mathrm{RA}$ volume, $\mathrm{ml} / \mathrm{m} 2$ & $24.19 \pm 7.53(21.78-26.60)$ \\
\hline \multicolumn{2}{|l|}{ Echocardiographic parameters $-3 \mathrm{D}^{*}$} \\
\hline LA max volume, $\mathrm{ml} / \mathrm{m} 2$, mean $\pm \mathrm{SD}(95 \% \mathrm{CI})$ & $42.32 \pm 8.96(38.97-45.67)$ \\
\hline LA min volume, $\mathrm{ml} / \mathrm{m} 2$, mean $\pm \mathrm{SD}(95 \% \mathrm{CI})$ & $24.29 \pm 8.01(21.30-27.28)$ \\
\hline \multicolumn{2}{|c|}{$\begin{array}{l}\text { ACEI - angiotensin-aldosterone-inhibitors, } \mathrm{BMI}=\text { body mass index, } \mathrm{BNP}=\text { brain natriuretic peptide } \\
\mathrm{LVEF}=\text { left ventricular ejection fraction, } \mathrm{LV}=\text { left ventricle, } \mathrm{LA}=\text { left atrium, } \mathrm{RA}=\text { right atrium } \\
3 \mathrm{DE}=\text { three-dimensional echocardiography, } 2 \mathrm{DE}=\text { bidimensional echocardiography } \\
\text { *data is reported as mean } \pm \mathrm{SD}(95 \% \mathrm{CI})\end{array}$} \\
\hline
\end{tabular}

TABLE 1. Patient characteristics $(n=40)$

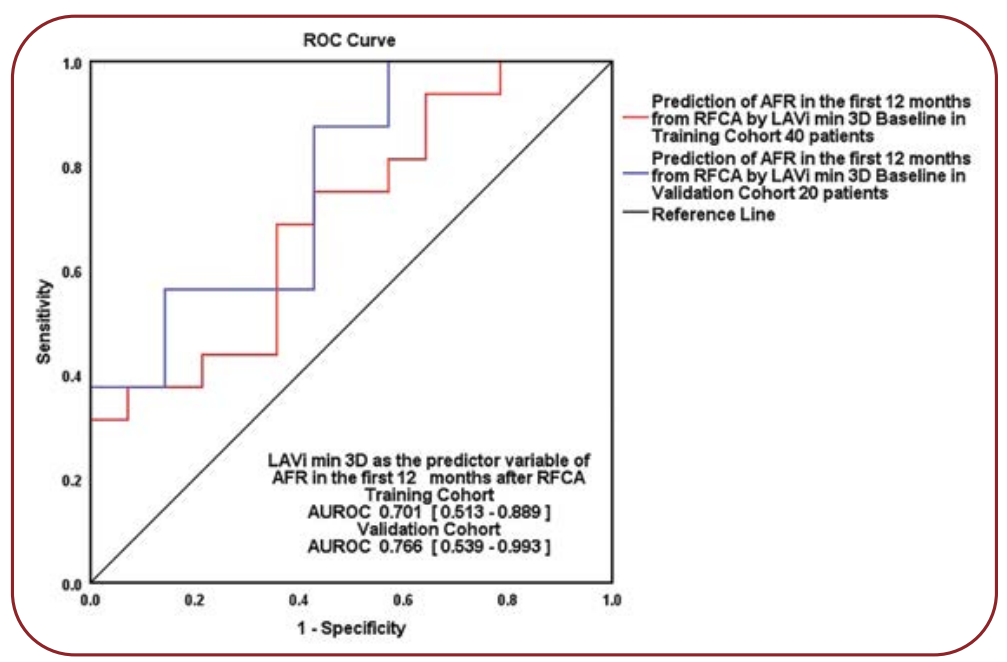

FIGURE 1. Baseline LAVi over $21.29 \mathrm{~mL} / \mathrm{m}^{2}$ as predictor of AFR in the first year and internal validation. Training cohort versus validation cohort, Hanley\&McNeil $\mathrm{p}=0.58 . \mathrm{LAVi}=$ left atrial index volume, $3 \mathrm{D}=$ three-dimensional echocardiography, $\mathrm{AFR}=$ atrial fibrillation recurrences 


\begin{tabular}{|c|c|c|c|c|c|c|}
\hline \multirow[t]{2}{*}{ Characteristics } & \multicolumn{3}{|c|}{ Pre-ablation echocardiography } & \multicolumn{3}{|c|}{12 months follow-up echocardiography } \\
\hline & No AFR & AFR & P- & No AFR & AFR & P-value \\
\hline & $0-12 \mathrm{~m}$ & $0-12 \mathrm{~m}$ & value & 12-24 months & 12-24 months & \\
\hline AFR pts, n/40 & $19 / 40$ & $21 / 40$ & & $29 / 40$ & $11 / 40$ & \\
\hline \multicolumn{7}{|c|}{ Bi-dimensional echocardiography } \\
\hline $\begin{array}{l}\text { LA AP diameter, } \\
\mathrm{mm}\end{array}$ & $\begin{array}{l}39.74 \pm 4.05 \\
(37.78-41.69)\end{array}$ & $\begin{array}{l}39.90 \pm 4.88 \\
(37.68-42.12)\end{array}$ & 0.907 & $\begin{array}{l}37.19 \pm 4.42 \\
(35.41-38.98)\end{array}$ & $\begin{array}{l}39.70 \pm 4.19 \\
(36.70-42.70)\end{array}$ & $0.36^{1}$ \\
\hline $\begin{array}{l}\text { LA mediolateral } \\
\text { diameter, } \mathrm{mm}\end{array}$ & $\begin{array}{l}42.26 \pm 4.04 \\
(40.32-44.21)\end{array}$ & $\begin{array}{l}43.86 \pm 4.43 \\
(41.84-45.87)\end{array}$ & 0.244 & $\begin{array}{l}40.73 \pm 4.51 \\
(38.91-42.55)\end{array}$ & $\begin{array}{l}46.50 \pm 4.5 \\
(43.28-49.72)\end{array}$ & 0.002 \\
\hline $\begin{array}{l}\text { LA superior- } \\
\text { inferior diameter, } \\
\mathrm{mm}\end{array}$ & $\begin{array}{l}54.53 \pm 6.60 \\
(51.34-57.71)\end{array}$ & $\begin{array}{l}54.76 \pm 6 \\
(52.03-57.49)\end{array}$ & 0.907 & $\begin{array}{l}52.81 \pm 5.08 \\
(50.75-54.86)\end{array}$ & $\begin{array}{l}58 \pm 5.71 \\
(53.91-62.09)\end{array}$ & 0.012 \\
\hline LAVi max, $\mathrm{ml} / \mathrm{m}^{2}$ & $\begin{array}{l}36.56 \pm 8.18 \\
(32.62-40.50)\end{array}$ & $\begin{array}{l}39.58 \pm 9.26 \\
(35.37-43.80)\end{array}$ & $0.44^{1}$ & $\begin{array}{l}33.62+7.30 \\
(30.67-36.57)\end{array}$ & $\begin{array}{l}42.89 \pm 9.82 \\
(35.86-49.91)\end{array}$ & $0.002^{1}$ \\
\hline LAVi $\mathrm{min}, \mathrm{ml} / \mathrm{m}^{2}$ & $\begin{array}{l}18.64 \pm 6.30 \\
(15.61-21.68)\end{array}$ & $\begin{array}{l}21.97 \pm 9.52 \\
(19.64-26.30)\end{array}$ & $0.323^{1}$ & $\begin{array}{l}16.68 \pm 4.84 \\
(14.72-18.64)\end{array}$ & $\begin{array}{l}22.67 \pm 8.59 \\
(16.53-28.82)\end{array}$ & $0.022^{1}$ \\
\hline \multicolumn{7}{|c|}{ Three-dimensional echocardiography } \\
\hline LAVi max, $\mathrm{ml} / \mathrm{m}^{2}$ & $\begin{array}{l}40.00 \pm 8.81 \\
(34.91-45.08)\end{array}$ & $\begin{array}{l}44.35 \pm 8.87 \\
(39.63-49.08)\end{array}$ & 0.189 & $\begin{array}{l}35.87 \pm 6.44 \\
(33.08-38.66)\end{array}$ & $\begin{array}{l}43.21 \pm 3.30 \\
(40.45-45.97)\end{array}$ & 0.005 \\
\hline LAVi $\mathrm{min}, \mathrm{ml} / \mathrm{m}^{2}$ & $\begin{array}{l}20.92 \pm 6.19 \\
(17.34-24.49)\end{array}$ & $\begin{array}{l}27.25 \pm 8.43 \\
(22.76-31.74)\end{array}$ & 0.028 & $\begin{array}{l}18.71 \pm 5.08 \\
(16.52-20.91)\end{array}$ & $\begin{array}{l}25.12 \pm 4.37 \\
(21.46-28.78)\end{array}$ & 0.004 \\
\hline
\end{tabular}

$\mathrm{AFR}=$ atrial fibrillation recurrences, $\mathrm{LA}=$ left atrium, $\mathrm{AP}=$ anteroposterior, $\mathrm{LAVi}=\mathrm{left}$ atrium indexed volume

* data is reported as mean $\pm \mathrm{SD}(95 \% \mathrm{Cl})$ and comparison was done with T-student test

TABLE 2.

Echocardiographic

${ }^{1}$ Mann-Whitney Test was used for comparison, as variables had nonparametric distributions characteristics

nine AF-free patients and 11 with $\mathrm{AF}$ recurrences: AUROC $=0.766,95 \% \mathrm{Cl}=0.539-0.993$, $\mathrm{p}=0.063$ ) (Figure 1).

We compared 3DE LAVi values from the 12-month assessment and determined that is the strongest predictor of outcome $(p=0.014)$, ex- plaining $36 \%$ of latter AFR. We calculated the Patients with 3DE min LAVi over the cut-off value $>22.49 \mathrm{~mL} / \mathrm{m}^{2} \quad$ (AUROC $=0.842$, $95 \% \mathrm{Cl}=0.688-0.996, \mathrm{p}=0.004,87.5 \%$ sensibility and $82.6 \%$ specificity), had a $29 \%$ higher risk of AFR after the first year $(\mathrm{OR}=1.297$,

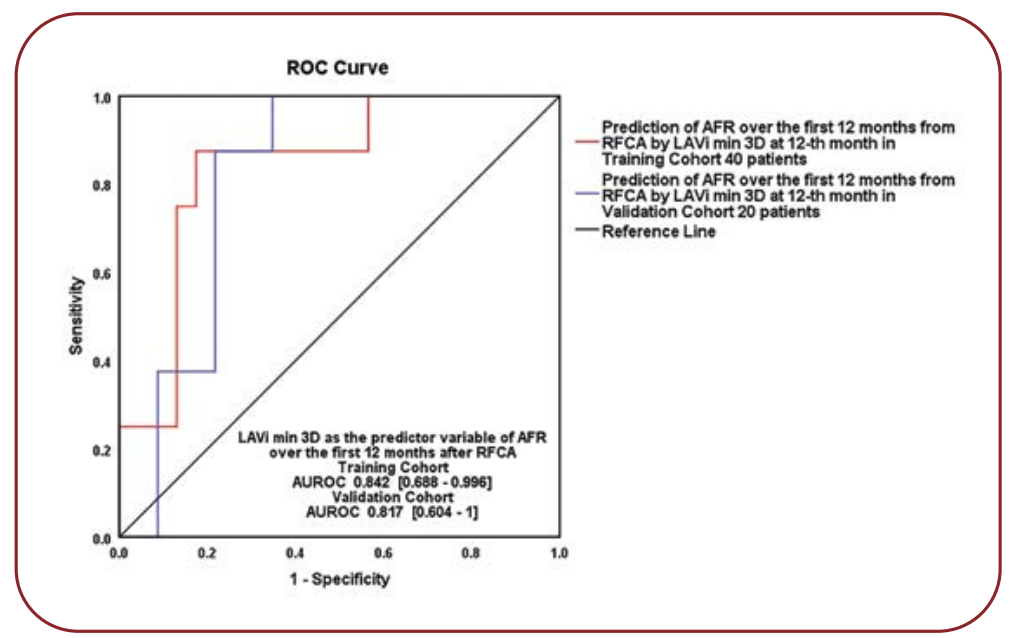

FIGURE 2. 12-month min LAVi over $22.49 \mathrm{~mL} / \mathrm{m}^{2}$ as predictor of AFR after the first year. Training cohort versus validation cohort, Hanley\&McNeil $p=0.79$. $\mathrm{LAVi}=$ left atrial index volume, $3 \mathrm{D}=$ three-dimensional echocardiography, $\mathrm{AFR}=$ atrial fibrillation recurrences 
$95 \% \mathrm{Cl}=1.054-1.597, \mathrm{p}=0.014)$. The prediction equation is the following: Ln (OR for AFR $>12$ months $)=-6.742+0.26 \times$ [3DE $\min$ LAVi]. We validated the result on a randomly assigned subgroup from our study population $($ AUROC $=0.817,95 \% \mathrm{Cl}=0.604-1 ; \mathrm{p}=0.045)$, with a good superposition of the two ROC curves (Figure 2).

3DE min LAVi shows a significant reverse remodeling after RFCA, with a decrease in mean volume by $5.24 \mathrm{~mL} / \mathrm{m}^{2}(\mathrm{p}=0.02) 12$-months after RFCA. Reverse remodeling is significant in AF-free patients $(p=0.047)$, but not in patients

\begin{tabular}{|c|c|c|c|c|c|}
\hline \multirow[b]{2}{*}{ Univariate Analysis } & \multirow{2}{*}{$\begin{array}{l}\text { Predictor for } \\
\text { AFR 0-12 } \\
\text { from baseline } \\
\text { 3DE Min LAVi }\end{array}$} & \multicolumn{4}{|c|}{$\begin{array}{l}\text { Predictor for AFR }>12 \text { months } \\
\text { from 12-months follow-up echocardiography }\end{array}$} \\
\hline & & 3DE Min LAVi & 2DE Min LAVi & $\begin{array}{l}\text { 3DE Max } \\
\text { LAVi }\end{array}$ & 2DE MaxLAVi \\
\hline Coefficient & 0.121 & 0.26 & 0.151 & 0.232 & 0.137 \\
\hline $\begin{array}{l}\text { Coefficient-Standard } \\
\text { Error }\end{array}$ & 0.059 & 0.106 & 0.072 & 0.098 & 0.061 \\
\hline $\begin{array}{l}\text { Coefficient- } \\
\text { Significance }\end{array}$ & 0.042 & 0.014 & 0.036 & 0.018 & 0.025 \\
\hline Intercept & -2.741 & -6.742 & -3.839 & -10.238 & -6.042 \\
\hline $\begin{array}{l}\text { Intercept-Standard } \\
\text { Error }\end{array}$ & 1.435 & 2.467 & 1.447 & 4.021 & 2.317 \\
\hline Intercept-Significance & 0.056 & 0.006 & 0.008 & 0.011 & 0.009 \\
\hline $\begin{array}{l}\text { Omnibus Tests } p \text { - } \\
\text { value }\end{array}$ & 0.022 & 0.003 & 0.014 & 0.003 & 0.005 \\
\hline AUROC & 0.701 & 0.842 & 0.750 & 0.875 & 0.838 \\
\hline Nagelkerke Pseudo- $R^{2}$ & 0.214 & 0.36 & 0.222 & 0.357 & 0.286 \\
\hline $\begin{array}{l}\text { Hosmer Lemeshow } \\
p \text {-value }\end{array}$ & 0.371 & 0.608 & 0.852 & 0.853 & 0.501 \\
\hline AIC & 40.213 & 30.683 & 40.531 & 30.781 & 38.577 \\
\hline $\mathrm{BIC}$ & 43.016 & 33.550 & 43.698 & 33.649 & 41.744 \\
\hline
\end{tabular}

AUROC=area under the operation curve, $\mathrm{AIC}=$ Akaike's Information Criterion, BIC=Bayesian Information Criterion

TABLE 3. Independent predictors of AFR

\begin{tabular}{|c|c|c|c|c|}
\hline \multirow[t]{2}{*}{ Characteristic } & \multirow[t]{2}{*}{ Odds Ratio } & \multirow{2}{*}{$\begin{array}{l}95 \% \mathrm{CI} \\
\text { lower value }\end{array}$} & & \multirow[t]{2}{*}{$\mathrm{p}$} \\
\hline & & & higher value & \\
\hline \multicolumn{5}{|c|}{ Bidimensional echocardiography } \\
\hline Minimum LAVi $>18.24 \mathrm{ml} / \mathrm{m}^{2}$ & 1.163 & 1.010 & 1.340 & 0.036 \\
\hline Maximum LAVi $>34.91 \mathrm{ml} / \mathrm{m}^{2}$ & 1.146 & 1.017 & 1.292 & 0.025 \\
\hline \multicolumn{5}{|c|}{ Three-dimensional echocardiography } \\
\hline Minimum LAVi $>22.49 \mathrm{ml} / \mathrm{m}^{2}$ & 1.297 & 1.054 & 1.597 & 0.014 \\
\hline Maximum LAVi $>38.79 \mathrm{ml} / \mathrm{m}^{2}$ & 1.261 & 1.041 & 1.527 & 0.018 \\
\hline
\end{tabular}


with AFR $(p=0.327)$. Patients who will no longer develop AFR after the first year also show a significant reverse remodeling of $\min 3 \mathrm{DE}$ LAVi $(p=0.034)$ compared to pre-ablation values.

We have also found significant differences between patients who would remain AF-free and those who would have AFR after the first year: medio-lateral and superior-inferior LA diameters, LA min and max volumes assessed by 2DE and 3DE; while all LAVi were found to be independent predictors of AFR 2DE min LAVi $(p=0.036), 3 D E$ max LAVi $(p=0.025)$ and 3DE max LAVi $(p=0.018)$ (Table 3 and Table 4).

\section{DISCUSSION}

The main findings of our study are as follows: LA anteroposterior (AP) diameter is not a prognostic marker for AF recurrences after RFCA, while LA remodeling evaluated by volumetric assessment adds important prognostic information.

Left atrium AP diameter as marker of LA dilation was intensely studied in relation to AFR risk after ablation. An increased diameter was associated with a higher risk of AFR (8). We did not find any differences in LA AP diameter with respect to AF recurrence at 12-month echocardiographic LA evaluation: superior-inferior, mediolateral LA diameters and LA volumes were significantly lower in patients with no AFR.

Left atrial volume reflects LA remodeling better than linear diameters and is more precise in assessing LA enlargement, a risk factor of AFR after ablation (9). Badano et al show that, by using only LA diameters and area measurements, more than $50 \%$ of patients may be misclassified regarding the degree of LA dilation, while 3D LAVi is more accurate than 2DE LAVi (10). The literature threshold of 2D LAVi over $34 \mathrm{~mL} / \mathrm{m}^{2}$ has a sensitivity of $70 \%$ and specificity of $91 \%$ to predict AF recurrences (11), while there is no cut-offs generally accepted for 3DE. Volumes assessed by 3D are larger compared with $2 \mathrm{D}$, normality ranges for $3 \mathrm{DE}$ versus $2 \mathrm{DE}$ : $\max \mathrm{LAVi} 43$ vs $35 \mathrm{~mL} / \mathrm{m}^{2}$ and $\min$ LAVi 18 vs $14 \mathrm{~mL} / \mathrm{m}^{2}$ (12).

With respect to the above discussed reference values, prior to intervention mean $\mathrm{LAVi}$ was higher in both study groups (arrhythmia-free and AFR groups). At 12-month follow-up, arrhythmia-free patients will demonstrate a significant decrease in LAV compared to those with
AFR. Conventional 2DE found no differences between groups, while 3DE enabled us to notice that min LAVi was lower in patients without AFR and also qualified for being a predictor of first year outcome after RFCA.

Most studies evaluated max LAVi as predictor of outcome after RF ablation. To our knowledge, limited data is available regarding LA min volume and its prognostic role in patients with AF. According to Fatema et al (13), min LA volume is associated with a first AF episode, while Schaaf et al proved (14) it to be the best predictor of paroxysmal AF. Motoc et al have also found that a 3DE min LAVi over $23.69 \mathrm{~mL} / \mathrm{m}^{2}$ was a predictor of AFR after paroxysmal AF ablation (15). We determined a cut-off over $21.29 \mathrm{~mL} / \mathrm{m}^{2}$ to predict first year AFR and explain our lower threshold as we did not exclude patients with AFR only in the blanking period.

\section{Study limitations}

This is a single center study with a small number of patients from a low-volume RFCA; therefore, larger clinical studies are warranted to confirm our findings. 3DE LAV was assessed with a non-dedicated software package and could not be compared to the gold standard method for chamber quantification: cardiac magnetic resonance. Nevertheless, the same software was used in other clinical trials and we enrolled a homogenous population, without any baseline clinical or biological parameters that may have influenced prognosis. Internal validation of our results showed a good superposition of the ROC curves.

\section{Future perspectives}

3DE can provide more accurate LA measurements and prognostic information about the outcome after $\mathrm{AF}$ ablation interventions. Routine measurement of minimum LAVi can impact clinical practice not only by selecting patients with a better chance to be "cured" by RFCA, but also by monitoring those who are at higher risk for $\mathrm{AF}$ recurrences.

\section{CONCLUSIONS}

trial remodeling is more accurately assessed using volumetric measurement by 3DE. 3DE min LAVi was the only independent predictor of outcome in the first year after RFCA, suggesting 
that subtle structural remodeling had an important role in triggering AF episodes. LA remodeling assessed by 3DE shows that minimum LAVi evaluated at 12 months after the intervention was the best predictor of long-term AF recurrence.
Conflicts of interest: none declared.

Financial support: none declared.

Acknowledgements: The authors of this paper

would like to thank Prof. Dr. Serban Balanescu,

Department of Cardiology, Elias Emergency

University Hospital, for his support.

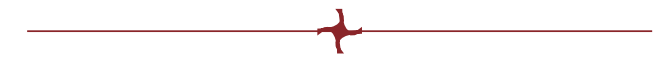

\section{R RFERENCES}

1. Blume GG, Mcleod CJ, Barnes ME, et al. Left atrial function: physiology, assessment, and clinical implications. Eur J Echocardiogr 2011;12:421-430.

2. Jeevanantham $\mathrm{V}$, Ntim $\mathrm{W}$, Navaneethan SD, et al. Meta-Analysis of the Effect of Radiofrequency Catheter Ablation on Left Atrial Size, Volumes and Function in Patients With Atrial Fibrillation. Am I Cardiol 2010;105:1317-1326.

3. Lester SJ, Ryan EW, Schiller NB, Foster E. Best method in clinical practice and in research studies to determine left atrial size. Am J Cardiol 1999;84:829-832.

4. Lang RM, Badano LP, Mor-Avi V, et al. Recommendations for Cardiac Chamber Quantification by Echocardiography in Adults: An Update from the American Society of Echocardiography and the European Association of Cardiovascular Imaging. Eur Heart J Cardiovasc Imaging 2015;16:233-271.

5. Liżewska-Springer $A$,

Dąbrowska-Kugacka A, Lewicka E, et al. Echocardiographic predictors of atrial fibrillation recurrence after catheter ablation: A literature review. Cardiol J 2020;27:848-856.

6. Kuusisto JK, Järvinen VM, Sinisalo JP.
Validation of 3D echocardiographic volume detection of left atrium by human cadaveric casts. BMC Med Imaging 2018;18:43.

7. Nagueh SF, Smiseth OA, Appleton CP, et al. Recommendations for the Evaluation of Left Ventricular Diastolic Function by Echocardiography: An Update from the American Society of Echocardiography and the European Association of Cardiovascular Imaging. J Am Soc Echocardiogr 2016;29:277-314.

8. Zhuang J, Wang Y, Tang K, et al. Association between left atrial size and atrial fibrillation recurrence after single circumferential pulmonary vein isolation: a systematic review and meta-analysis of observational studies. Europace 2012;14:638-645.

9. Njoku A, Kannabhiran M, Arora R, et al. Left atrial volume predicts atrial fibrillation recurrence after radiofrequency ablation: a meta-analysis. EP Europace 1 2018;20:33-42.

10. Badano LP, Pezzutto N, Marinigh R, et al. How many patients would be misclassified using $\mathrm{M}$-mode and two-dimensional estimates of left atrial size instead of left atrial volume? A three-dimensional echocardiographic study: J Cardiovasc Med 2008;9:476-484.

11. Shin S-H, Park M-Y, Oh W-J, et al. Left
Atrial Volume Is a Predictor of Atrial Fibrillation Recurrence After Catheter Ablation. J Am Soc Echocardiogr 2008;21:697-702.

12. Badano LP, Miglioranza MH, Mihaila S, et al. Left Atrial Volumes and Function by Three-Dimensional Echocardiography: Reference Values, Accuracy, Reproducibility, and Comparison With Two-Dimensional Echocardiographic Measurements. Circ Cardiovasc Imaging [Internet].2016 [cited on 2021];9. https:// www.ahajournals.org/doi/10.1161/ CIRCIMAGING.115.004229

13. Fatema K, Barnes ME, Bailey KR, et al. Minimum vs. maximum left atrial volume for prediction of first atrial fibrillation or flutter in an elderly cohort: a prospective study. Eur J Echocardiogr 2008;10:282-286.

14. Schaaf M, Andre P, Altman M, et al. Left atrial remodelling assessed by $2 \mathrm{D}$ and 3D echocardiography identifies paroxysmal atrial fibrillation. Eur Heart J Cardiovasc Imaging 2017:18:46-53.

15. Motoc A, Abugattas J-P, Roosens B, et al. Left atrium remodeling predicts late recurrence of paroxysmal atrial fibrillation after second generation cryoballoon ablation.

Cardiovasc Ultrasound 2018;16:19. 